\title{
Relationship between Molecular Properties of some Photosystem II Inhibitors and their Activity on Triazine-Resistant and -Susceptible Chloroplasts
}

\author{
S. Creuzet, B. Gilquin, and J. M. Ducruet \\ Service de Biophysique, Departement de Biologie CEA/INRA Saclay, \\ 91191 Gif-sur-Yvette, France \\ Z. Naturforsch. 44c, 435-443 (1989); received January 9, 1989 \\ Dedicated to Professor Achim Trebst on the occasion of his 60th birthday \\ Photosystem II, Herbicide, QSAR, Resistance, Molecular Modelling \\ The conformations and electronic properties of several urea/amide, uracil, s-triazine and \\ methylthiopyrimidine inhibitors of photosystem II were determined using molecular mechanics \\ (CHARMM, SYBYL) or quantum semi-empirical (MNDO, AM1) methods. Spectroscopic \\ measurements of the in vitro hydrogen bonding capacity of these compounds were also carried \\ out. The validity of the calculated values was estimated from experimental measurements. The \\ conformational and electronic properties of the inhibitors studied are then discussed in terms of \\ their mechanism of action on the D 1 site and its modification by triazine resistance.
}

The properties of herbicide-resistant mutants modified at the PS II site of inhibition have been thoroughly investigated, first in different weed species [1], then in algae [2] and cyanobacteria [3]. The "resistance" mutations could be ascribed to an amino-acid substitution [4] within the D1 polypeptide, which binds a plastoquinone molecule to form the secondary acceptor $\mathrm{Q}_{\mathrm{B}}$ of PS II.

The chloroplasts from resistant plants were first characterized by a considerably decreased susceptibility to atrazine inhibition, contrasting with an almost unchanged susceptibility to diuron. This suggested that the binding sites of these two compounds were distinct, albeit overlapping $[1,5]$ in order to explain the competitive displacement of diuron by atrazine [6]. In the overlapping model, only the atrazine-specific binding domain would be altered by the resistance-confering mutation.

However, when other PS II inhibitors are taken into account, a clear-cut distinction between diuronlike and atrazine-like compounds, according to their behavior towards atrazine resistance, has to be mitigated. Classes of inhibitors such as triazinones or uracils [1] are intermediate between diuron and atrazine, as judged by the ratios $(\mathrm{R} / \mathrm{S})$ of their halfinhibitory concentrations in resistant versus susceptible chloroplasts. Among inhibitors structurally re-

\section{Reprint requests to Dr. S. Creuzet.}

Verlag der Zeitschrift für Naturforschung, D-7400 Tübingen 0341-0382/89/0500-0435 \$01.30/0 lated to diuron, some urea and amide derivatives exhibit R/S values higher than $10[7,8]$. Much higher R/S values were even reported, in Amaranthus retroflexus, for several urea inhibitors [9]. Furthermore, these variations of the $\mathrm{R} / \mathrm{S}$ ratios of amide/urea derivatives could be related to two structural features which antagonize, to some extent, the effect of atrazine resistance:

- In the phenyldimethylurea series, the $\mathrm{R} / \mathrm{S}$ was inversely related to the hydrophobicity of the $\mathrm{N}$ phenyl substituent [7], which is absent in triazines and uracils. This was further evidenced by the synthesis [10] of N-phenylated triazines, displaying both a strong inhibitory power and $\mathrm{R} / \mathrm{S}$ values $(\times 15)$ much lower than those of triazines.

- Comparisons of phenylureas and triazines with equivalent partition coefficients showed that the dimethylamino electron-repelling substituent of ureas [11] is antagonistic towards the effects of atrazine resistance as compared with the alkyl substituent of amides [7]. This suggests a role for a nucleophilic carbonyl in a resistance-independent interaction with an electrophilic group (proton donor?) of the $Q_{B}$ pocket.

These properties raise the question of a possible influence of the "resistance" mutation on a molecular interaction which could be common to urea/amide and triazine inhibitors $[11,12]$.

In Chlamydomonas reinhardii, a Ser $264 \rightarrow$ Ala mutation [2] on D1 induces a strong resistance to both diuron and atrazine, in sharp contrast with the weak effect of the Ser $264 \rightarrow$ Gly mutation on diuron 
activity [4]. This further outlines how close are the binding domains of ureas and triazines.

The NH-CX is common to most inhibitors [11, 12], with the exception of phenolics, but the presence of an unsubstituted hydrogen is not a strict prerequisite for inhibitory activity $[13,14]$. Hence, the minimum pattern proposed by Trebst [15] consists of a sp $\mathrm{S}^{2}$-hybridized carbon of a $\mathrm{C}=\mathrm{X}$ nucleophilic group $(\mathrm{X}=\mathrm{O}, \mathrm{N}, \mathrm{S})$ linked to a positively charged nitrogen and to a bulky hydrophobic substituent. The possible role of the $\mathrm{NH}-\mathrm{CX}$ moiety in hydrogen bonding has been hypothesized from structure-activity relationships [16] and molecular orbital calculations [17]. It has recently been confirmed in bacterial reaction centers, where the triazine terbutryne is hydrogen bonded: one aromatic nitrogen to a peptide $\mathrm{NH}$ and one NH to the oxygen of a serine [18]. However, in spite of sequence analogies between $\mathrm{L}$ and $\mathrm{M}$ bacterial subunits and the D1/D2 polypeptides of PS II $[19,20]$, diuron is completely inactive on bacterial photosynthesis and triazines are 10-100-fold less active than in PS II.

The difficulty of classifying PS II inhibitors as diuron-like or atrazine-like compounds according to their loss of activity on triazine-resistant chloroplasts leads to consider the inhibitory structures as a whole, beyond the usual QSAR categories, from the point of view of their tridimensional structures and electronic properties.

In this work, we have applied different methods to calculate the molecular properties of amide/ureas, uracils and triazines. Methylthiopyrimidines, a new class of powerful PS II inhibitors [21], were also included, since they allow comparisons with triazine structures. These results were compared with physico-chemical measurements and in vivo data.

\section{Material and Methods}

\section{Hill reaction activity}

The oxygen evolution by uncoupled thylakoids, with ferricyanide as an electron acceptor, was measured with a Clark electrode, as previously described [7].

Molecular mechanics and quantum calculations

The procedure generally applied was to determine initial sets of coordinates by a molecular mechanics method (CHARMM [22] or SYBYL-TRIPOS [23]) and, using the resulting conformations, to calculate the electronic properties of molecules (partial charges, dipole, ionization potential, electronic affinity) by a semi-empirical quantum method (MNDO [24], AM1 [25]). Rotational barriers were also determined by these quantum methods.

\section{Infra-red studies of phenol-inhibitor complexes}

IR spectra were performed in absorbance mode on a Beckman DK2A spectrometer in $10 \mathrm{~mm}$ quartz cells, as previously described $[26,27]$. The solvent was spectroscopic grade carbon tetrachloride. In the $0-4 \mathrm{~mm}$ concentration range, the absorbance of the free longitudinal $\mathrm{OH}$ vibration of $p$-octylphenol and $p$-chlorophenol was proportional to the phenol concentration, although weak autoassociation bands $(<5 \%)$ could be noticed.

\section{Results}

Activity of amide/ureas on triazine-resistant chloroplasts

In Table I the half-inhibitory concentrations $\left(I_{50}\right)$ in resistant and susceptible chloroplasts from Chenopodium album are given for homologous phenylureas and phenylamides. A decrease of the number of chlorine substituents on the phenyl ring led to an increase of the R/S values in both phenylureas and phenylamides. This resistance-antagonizing effect of chlorination can be related to an increase of hydrophobicity $(\pi)$ rather than to an electron attraction (Hammett $\sigma$ ) since a 4-isopropyl electron-repelling substituent in isoproturon $(\sigma=0.15)$ led also to a $\mathrm{R} / \mathrm{S}$ ratio lower than that of fenuron $(\sigma=0)$.

Amide inhibitors showed higher $\mathrm{R} / \mathrm{S}$ than the homologous N-phenyl dimethylureas, although the partition coefficient of propanil was higher than that of diuron [7]. 4-Chloropropanilide, which combines a decreased phenyl hydrophobicity with an absence of a dimethylamino substituent on the carbonyl, provides an example of a compound structurally close to diuron, hence likely to bind to the same site, but 10fold more affected by triazine resistance.

\section{Molecular conformations}

In Rhodopseudomonas viridis [18], double hydrogen bonds are formed by one $-\mathrm{NH}-\mathrm{C}=\mathrm{N}-$ of ter- 
Table I. Half-inhibitory concentrations in triazine-resistant (R) and -susceptible (S) Chenopodium album chloroplasts and R/S $\left(I_{50}(\mathrm{R}) / I_{50}(\mathrm{~S})\right)$ ratios. Electronic (Hammett $\left.\sigma\right)$ and hydrophobic $(\pi)$ parameters of the $\mathrm{N}$-phenyl.<smiles>[R2]C(=O)N([R2])[2H]</smiles>

\begin{tabular}{llllrrrr}
\hline & $\mathrm{R}_{1}$ & $\mathrm{R}_{2}$ & $I_{50}(\mathrm{~S})$ & $I_{50}(\mathrm{R})$ & $\mathrm{R} / \mathrm{S}$ & $\sigma$ & $\pi$ \\
\hline Diuron & 3,4-dichlorophenyl & dimethylamino & 0.05 & 0.08 & 1.7 & 0.60 & 1.46 \\
Propanil & 3,4-dichlorophenyl & ethyl & 0.13 & 0.65 & 5.0 & 0.60 & 1.46 \\
Monuron & 4-chlorophenyl & dimethylamino & 0.35 & 2.70 & 7.7 & 0.23 & 0.70 \\
4-Chloropropanilide & 4-chlorophenyl & ethyl & 4.00 & 70 & 17.5 & 0.23 & 0.70 \\
Fenuron & phenyl & dimethylamino & 3.20 & 36 & 11.2 & 0.00 & 0.00 \\
Isoproturon & 4-isopropylphenyl & dimethylamino & 0.24 & 0.78 & 3.2 & -0.15 & 1.30 \\
\hline
\end{tabular}

butryne with, respectively, Ser L 223 (proton acceptor) and a peptide NH of Ile L 224 (proton donor). In order to examine whether such double bonds would be possible in PS II between the $\mathrm{NH}-\mathrm{C}=\mathrm{N} /$ $\mathrm{NH}-\mathrm{C}=\mathrm{O}$ moieties and common components of the site, the distances between hydrogens of $\mathrm{NH}$ and aromatic nitrogens of the triazine ring or carbonylic oxygens of ureas, amides and uraciles were determined.

The three-dimensional conformation of diuron was computed by two methods of molecular mechanics, using the CHARMM or SYBYL force fields. In both cases, energy values according to the dihedral angle $\mathrm{NH}-\mathrm{CO}$ showed that the planar trans conformation was the most stable one, at different angles of the amide/phenyl planes, while the possibility of a cis-amide form was strongly unfavored. An energy minimum estimated at $4 \mathrm{kcal} / \mathrm{mol}$ above the planar trans conformation corresponded to a nonplanar cis form, with the planes of the phenyl ring and the dimethylamino tilted in opposite directions. In the planar trans form of $\mathrm{NH}-\mathrm{CO}$, the phenyl ring was found in the same plane by CHARMM, but tilted with a $30^{\circ}$ angle by SYBYL. This second configuration is in agreement with cristal structure of diuron and was confirmed by the semi-empirical quantum method AM1, in a good improvement over MNDO which failed to predict the dimethylamino conformation (Table II).

Similar results were obtained for other urea or anilide derivatives, which implies that only the trans $\mathrm{NH}-\mathrm{CO}$ is involved in the interaction with the target, eventually through a double hydrogen bond. Swep, a phenylcarbamate inhibitor, was an exception since a non planar $\left(30^{\circ}\right)$ cis form was possible at
Table II. Values of dihedral angles between phenyl/amide planes $(\Phi / \mathrm{NH}-\mathrm{CO})$ and amide/dimethylamino planes (NH-CO/DMA) for diuron trans, as predicted by different methods of calculation or measured by X-ray diffraction.

\begin{tabular}{lcc}
\hline & $\Phi / \mathrm{NH}-\mathrm{CO}$ & $\mathrm{NH}-\mathrm{CO} / \mathrm{DMA}$ \\
\hline CHARMM (standard) & $0^{\circ}$ & $0^{\circ}$ \\
SYBYL & $32^{\circ}$ & $0^{\circ}$ \\
MNDO & $30^{\circ}$ & $90^{\circ}$ \\
AM 1 & $31^{\circ}$ & $8^{\circ}$ \\
Crystallography [27] & $34^{\circ}$ & $0^{\circ}$ \\
\hline
\end{tabular}

a $1.5 \mathrm{kcal} / \mathrm{mol}$ higher energy than the trans form, with an energy barrier of only $2.5 \mathrm{kcal} / \mathrm{mol}$. This would allow a flip-flop between the cis and trans forms, which may explain the unusually low activity of this compound compared to propanil $[7,11]$, in spite of a greater partition coefficient.

In uracils (lenacil), the $\mathrm{CO}-\mathrm{NH}$ moiety is forced into the cis planar form by the cyclic structure, with a $\mathrm{O} / \mathrm{H}$ distance of $2.4 \AA$, the same as in the virtual cisdiuron (Fig. 1). This conflicts with the above suggestion that the trans-amide form interacts with the target $(\mathrm{O} / \mathrm{H}=3.1 \AA)$. Moreover, the carbonyl group distant from the $\mathrm{NH}$ is liable to form an hydrogen bond, although the $\mathrm{O} / \mathrm{H}$ distance is much higher $(\mathrm{O} / \mathrm{H}=4.95 \AA)$.

In triazines, the $\mathrm{NH}$-alkyl chains can rotate between two energy minima with an energy difference of only $0.3 \mathrm{kcal} / \mathrm{mole}$ (Fig. 2), corresponding to the alkyl chain in the plane of the triazine ring. A rotational energy barrier of $12 \mathrm{kcal} / \mathrm{mol}$, computed by AM1, indicates that four stable slowly interchanging conformers exist in a triazine molecule, as a combination of the cis/trans positions (Fig. 1) of the two 
<smiles>[2H]N(CCCCCC)c1nc(N)c(SC)c(Cl)n1</smiles>

methylthiopyrimidine

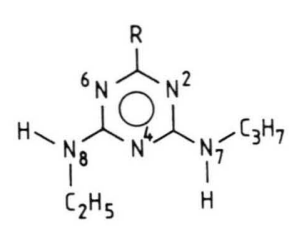

$s$ - triazine

amide $/$ urea

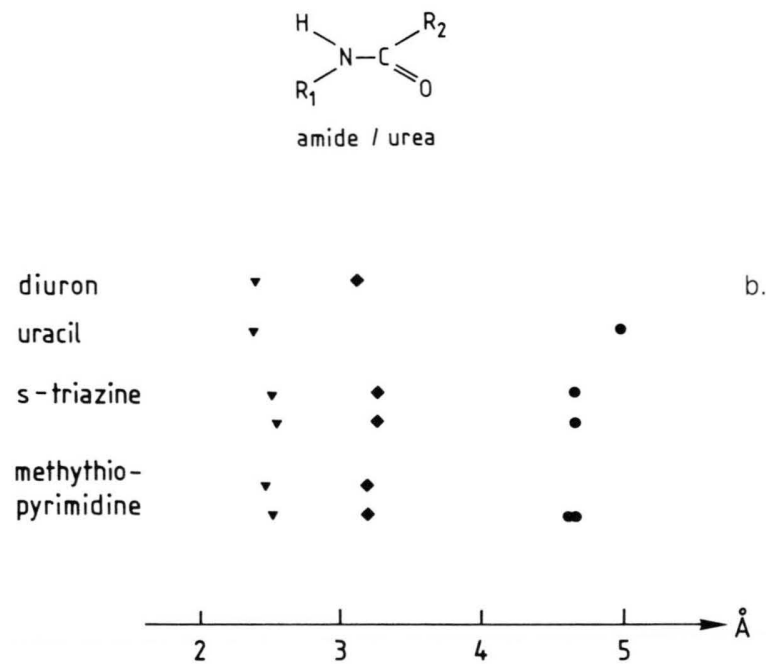<smiles>Cc1[nH]c(=O)n(P)c(=O)c1Cl</smiles>

uracil

Fig. 1. a. Structure and atom numbering of amide/ureas, uracil (terbacil), triazines (ametryne and atrazine) and chloro-methylthiopyrimidine. b. Distances calculated, after SYBYL minimization, between hydrogens of $\mathrm{NH}$ groups and oxygens of carbonyl (amide/ureas, uracil) or nitrogen of aromatic ring (triazines, methylthiopyrimidine).

alkyl chains. Calculations under fixed or flexible geometry led to similar values of rotational energy barrier, which can be entirely ascribed to the electronic conjugation between the lateral nitrogens and the aromatic triazine ring. Fig. 1 shows that three distances between the NH hydrogens and aromatic nitrogens are possible, namely $2.55 \AA$ (equivalent to cis-diuron or uracil $\mathrm{NH}-\mathrm{CO}$ ), $3.25 \AA$ (equivalent to trans-diuron) and $4.65 \AA(0.3 \AA$ shorter than the $\mathrm{NH}$ /para-carbonyl distance of uracils).

The methylthiopyrimidines [21] provide further informations. These compounds are structurally related to s-triazines, but one of the ring nitrogens is absent and its position corresponds to a methylthio substituent. Furthermore, an unsubstituted $\mathrm{NH}_{2}$ is an absolute requisite for inhibitory activity. Fig. 1 shows that the $\mathrm{H} / \mathrm{N}$ distances also fall in the three

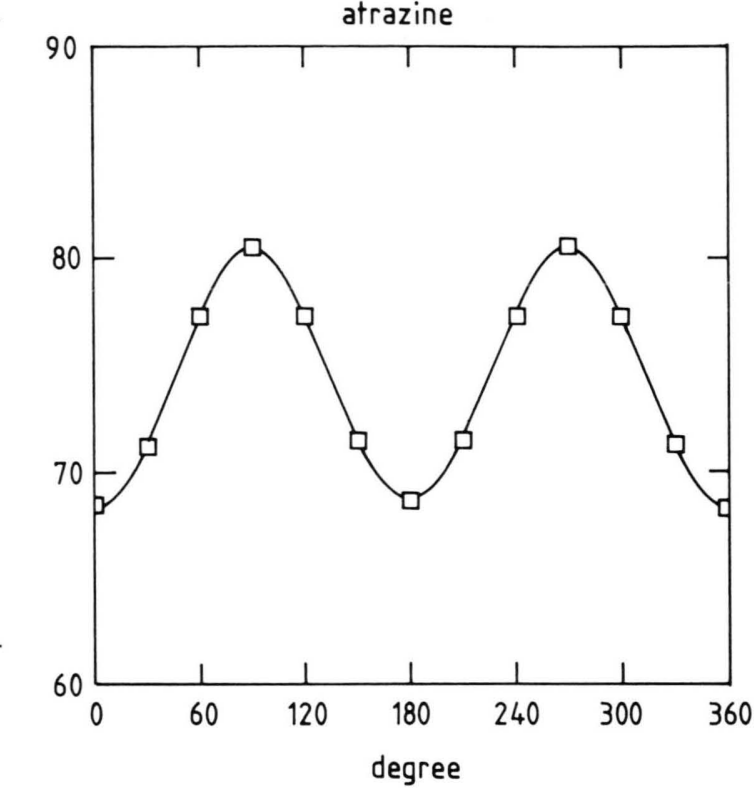

Fig. 2. Variations of the formation energy $(\mathrm{kcal} / \mathrm{mol})$ of atrazine at different angles between the triazine ring and one of the lateral $\mathrm{NH}$-alkyl chains. The position $0^{\circ}$ corresponds to a $\mathrm{NH}$ in the direction of chlorine.

clusters at $2.5 \AA, 3.2 \AA$ and $4.7 \AA$ previously found for urea/amides, uracils and triazines.

\section{Electronic parameters}

The electronic parameters (partial atomic charges, dipoles, ionization potentials) of the inhibitors here studied were obtained by applying the semi-empirical methods MNDO and AM1 on the geometric conformation generated by the SYBYL force field.

The charges obtained by MNDO are listed in Table 3 . The triazine ring nitrogens $(-0.42$ to 0.47$)$ hold the most negative net charges. An equivalent negative charge $(-0.442)$ was found for the pyrimidine ring nitrogen close to the methylthio substituent but the ring nitrogen close to chlorine was less charged $(-0.397)$ than the equivalent chlorineadjacent nitrogen of atrazine $(-0.430)$. The negative charge on the carbonyl oxygen of phenylureas was slightly modified by the inductive influence of the phenyl substituent, from diuron $(-0.418)$ to isoproturon $(-0.421)$. However, the replacement of the dimethylamino substituent of urea by an ethyl or a methoxy led to a large decrease of the oxygen net charge in propanil $(-0.359)$ and swep $(-0.352)$. 
Table III. Values of ionization potentials (IP), dipoles and net charges for different inhibitors, as calculated by MNDO on the conformation given by SYBYL-TRIPOS. The numbering of atoms in terbacyl, ametryne, atrazine and methylthiopyrimidine are given in Fig. 1 a.

\begin{tabular}{|c|c|c|c|c|c|c|c|c|}
\hline & & & IP & Dipole & Net charg & & & \\
\hline Amide/urea & $\mathrm{R}_{1}$ & $\mathrm{R}_{2}$ & & & $\mathrm{O}$ & $\mathrm{C}$ & $\mathrm{N}$ & $\mathrm{H}$ \\
\hline $\begin{array}{l}\text { Diuron } \\
\text { Monuron } \\
\text { Fenuron } \\
\text { Cycluron } \\
\text { Isoproturon } \\
\text { Propanil } \\
\text { Swep }\end{array}$ & $\begin{array}{l}\text { 3,4-diCl } \Phi \\
4-\mathrm{Cl} \Phi \\
\Phi \\
\text { cyclo-octyl } \\
4 \text {-iPr } \Phi \\
\text { 3,4-diCl } \Phi \\
\text { 3,4-diCl } \Phi\end{array}$ & $\begin{array}{l}\text { dimethylamino } \\
\text { dimethylamino } \\
\text { dimethylamino } \\
\text { dimethylamino } \\
\text { dimethylamino } \\
\text { ethyl } \\
\text { methoxy }\end{array}$ & $\begin{array}{r}9.37 \\
9.12 \\
8.88 \\
10.07 \\
8.82 \\
9.45 \\
9.43 \\
9.55\end{array}$ & $\begin{array}{l}5.18 \\
4.99 \\
3.59 \\
3.45 \\
3.57 \\
4.06 \\
3.78 \\
4.71\end{array}$ & $\begin{array}{l}-0.4165 \\
-0.4168 \\
-0.4188 \\
-0.4326 \\
-0.4189 \\
-0.3562 \\
-0.4195 \\
-0.3641\end{array}$ & $\begin{array}{l}0.4821 \\
0.4817 \\
0.4816 \\
0.4842 \\
0.4809 \\
0.3451 \\
0.4851 \\
0.4748\end{array}$ & $\begin{array}{l}-0.3531 \\
-0.3541 \\
-0.3537 \\
-0.4232 \\
-0.3537 \\
-0.3408 \\
-0.3267 \\
-0.3660\end{array}$ & $\begin{array}{l}0.1954 \\
0.1927 \\
0.1900 \\
0.1881 \\
0.1904 \\
0.2031 \\
0.2147 \\
0.1960\end{array}$ \\
\hline Uracil & & & & & $\mathrm{O}$ & $\mathrm{C}$ & $\mathrm{N}$ & $\mathrm{H}$ \\
\hline Terbacil & & & 9.88 & 3.14 & $\begin{array}{l}-0.3809_{7} \\
-0.3262_{8}\end{array}$ & $\begin{array}{l}0.4699_{2} \\
0.3860_{4}\end{array}$ & $-0.3076_{1}$ & 0.2282 \\
\hline Triazine & $\mathrm{R}$ & & & & $\mathrm{N}$ & $\mathrm{C}$ & $\mathrm{N}$ & $\mathrm{H}$ \\
\hline $\begin{array}{l}\text { Atrazine } \\
\text { Ametryne }\end{array}$ & $\begin{array}{l}\text { chloro } \\
\text { methylthio }\end{array}$ & & 9.75 & 3.52 & $\begin{array}{l}-0.4224_{2} \\
-0.4652_{4} \\
-0.4198_{6} \\
-0.4519_{2} \\
-0.4680_{4} \\
-0.4103_{6}\end{array}$ & $\begin{array}{l}0.3956_{3} \\
0.3955_{5} \\
0.3929_{3} \\
0.3888_{5}\end{array}$ & $\begin{array}{l}-0.3328_{7} \\
-0.3411_{8} \\
-0.3374_{7} \\
-0.3432_{8}\end{array}$ & $\begin{array}{l}0.2236 \\
0.2213 \\
0.2188 \\
0.2191\end{array}$ \\
\hline \multicolumn{5}{|c|}{ Methylthiopyrimidines } & $\mathbf{N}$ & $\mathrm{C}$ & $\mathrm{N}$ & $\mathrm{H}$ \\
\hline $\mathrm{A}_{3}$ & & & 9.11 & 3.29 & $\begin{array}{l}-0.4398_{4} \\
-0.3910_{6}\end{array}$ & $\begin{array}{l}0.3657_{3} \\
0.3906_{5}\end{array}$ & $\begin{array}{l}-0.3431_{7} \\
-0.3420_{8}\end{array}$ & $\begin{array}{l}0.2208 \\
0.2128 \\
0.2207\end{array}$ \\
\hline
\end{tabular}

The rotation of methoxy or methylthio groups in swep and ametryne respectively, influenced the adjacent nucleophilic charge, the highest charge corresponding to a methyl in a cis position in the same plane.

The charge distribution obtained by AM1, in its latest release parametrized for halogens [29], is slightly different from that obtained by MNDO. Particularly, charges on the ring nitrogens of triazines are proportionally lower by AM1 than by MNDO, as compared to carbonyl charges (Fig. 3).

Positive charges on nitrogen and hydrogen of $\mathrm{NH}$ were slightly higher in triazines than in ureas/amides,

Fig. 3. Relation between the association constant $K$ of $p$-chlorophenol/inhibitor complexes (Table IV) and the net charges on $\mathrm{C}=\mathrm{X}$ groups as calculated by MNDO (closed symbols) or AM 1 (open symbols). The horizontal bars indicate the domain of charge variation in swep (rotation of the methoxy substituent) and ametryne (rotation of the methylthio substituent). a: swep, b: diuron, c: isoproturon, $\mathrm{d}$ : cycluron, e: atrazine, f: ametryne. suggesting a greater acidity of the proton, hence a higher hydrogen bonding capacity with a proton acceptor $[26,27]$.

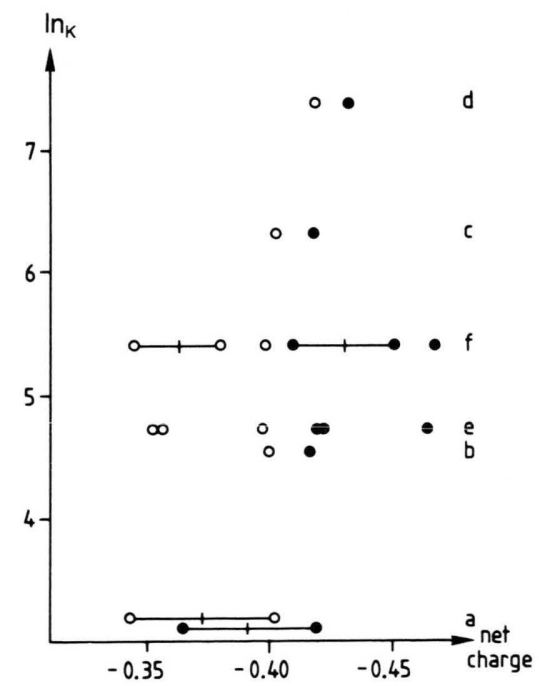




\section{Hydrogen bonding with phenolic protons}

These results can be compared with the hydrogen bonding capacity of the $\mathrm{C}=\mathrm{X}$ moiety of PS II inhibitors, as measured by their interactions with $p$ octylphenol and $p$-chlorophenol in carbon tetrachloride. The IR longitudinal $\mathrm{OH}$ absorbance of the uncomplexed phenol $\left(3610 \mathrm{~cm}^{-1}\right.$ for $p$-chlorophenol) was reduced in the presence of urea/amides or triazines, with an association constant [30] given in Table IV. The absorbance of the NH $\left(3470 \mathrm{~cm}^{-1}\right.$ for urea, $3445 \mathrm{~cm}^{-1}$ for triazines) was unchanged in the presence of phenols. This decrease in intensity of the free $\mathrm{OH}$ vibration corresponded to the appearence of a well-defined broad band at lower frequencies for amides/ureas only. The frequency shifts between the free and bound phenolic $\mathrm{OH}$ are listed in Table IV. The shift was larger for $p$-chlorophenol than for $p$ octylphenol, as expected for an hydrogen bond with a more acidic proton. A strong frequency shift occurred with cycluron, demonstrating that the aromatic ring of phenylureas was not involved in the interaction. However, a comparison between neburon (a
$\mathrm{CCl}_{4}$-soluble analog of diuron) and isoproturon, showed an important inductive effect of the phenyl ring, much larger than could be expected from the weak variations of the net charge on the oxygen carbonyl from MNDO calculations (Table III). In swep, however, the low negative charge on the carbonyl (Table III) resulted in a low hydrogen bonding capacity (Table IV). The hydrogen bonding phenolamide complexes have been thoroughly studied, and a $\Delta H$ can be computed [31] from the frequency shift.

With triazines, only a featureless increase of absorbance at lower frequencies could be observed, resulting either from the different proton-bonding properties of the three ring nitrogens or from the peculiar properties of the $=\mathrm{N}$...HO - hydrogen bonds [32, 33]. The association constants $K$ (Table IV) calculated from the free $\mathrm{OH}$ vibration are comparable to those obtained for ureas. This constant was greater for ametryne than for atrazine, in agreement with the charge differences on ring nitrogens 2 and 6 for these two compounds and with the relative protonation $\mathrm{pKs}$ of methylthiotriazines and chlorotriazines respectively [34].

Table IV. IR frequency shifts of the longitudinal vibration of the phenolic hydroxyl, $\Delta H$ [31] and association constants $K$ of complexes between $p$-octylphenol or $p$-chlorophenol and some PS II inhibitors. Neburon was taken as a CC 14-soluble analog of diuron.

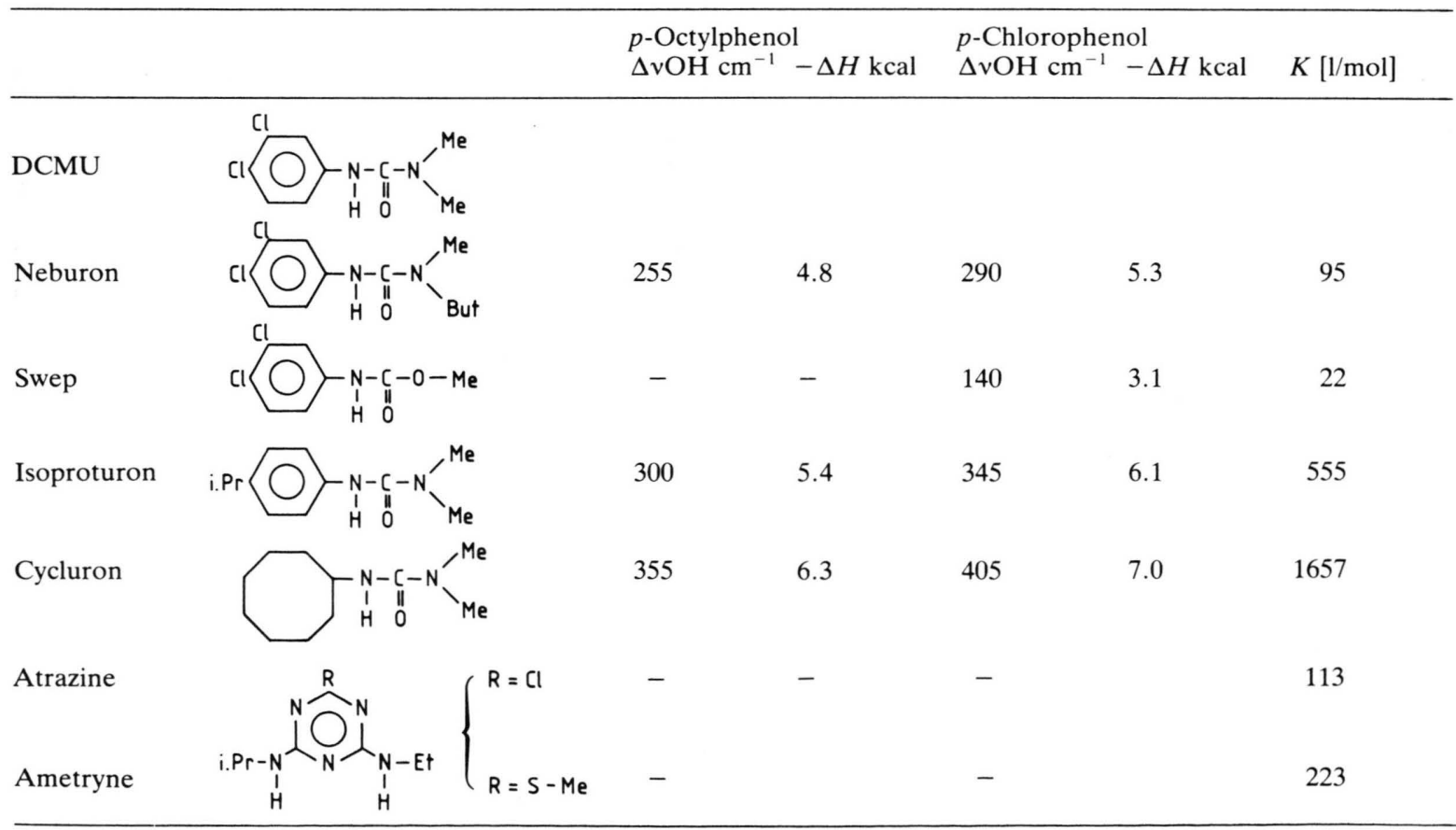


An overall positive correlation (Fig. 3) could be found between the net charges of the $\mathrm{C}=\mathrm{X}$ groups computed by SYBYL/MNDO (Table III) or SYBYL/ AM1 methods and the association constant of their hydrogen bonding complex with $p$-chlorophenol (Table IV).

Although hydrogen bonding is mainly an electrostatic phenomenon [35], it cannot be entirely related to the net charge of a nucleophilic atom. Neighbouring charged atoms can influence the electric field, as suggested by point-charge potential maps [17]. Moreover, the molecular polarisability is likely to play a role since hydrogen bonding induces charge movements $[36,37]$. This might explain why isoproturon-phenol complexes are stronger than those formed by diuron (Table IV), whereas the net carbonyl charges are almost equivalent (Table III).

The values of dipole moments (Table III) obtained here are similar to those proposed by Shipman [38].

The lowest ionization potentials (Table III) were those of phenylureas and were highly dependent on the phenyl ring substituents. This indicates an electron donating capacity in charge transfer complexes. Tetracyanoethylene, a compound with a high electronic affinity and no visible absorption, has been extensely used as an electron acceptor in charge transfer complex studies [38]. In the presence of phenylureas only, a visible absorption band develops [27], the frequency of which is proportional to the ionization potential of the electronic donor - here the phenylurea. The maximum frequency of this absorption band is linearly related to the ionization potential found by AM1 and MNDO (data not shown). This provides a control of the validity of results obtained by both methods, without any evidence for a role in vivo.

\section{Discussion}

The results in Table IV demonstrate the capacity of the $\mathrm{C}=\mathrm{X}$ moiety of both amide/ureas and triazines to form hydrogen bonds, attaining $5 \mathrm{kcal} / \mathrm{mol}$, with strong proton donors such as phenols. However, one single hydrogen bond cannot explain the in vivo interaction energy, since a $\Delta H=-11 \mathrm{kcal} / \mathrm{mol}$ has been found for metribuzine [40]. Although cycluron and diuron are isohydrophobic [7] and cycluronphenols complexes are 15 -fold stronger than those formed by diuron, this latter compound is 20 -fold more active in vivo. In the assumption of a $\mathrm{C}=\mathrm{X}$... site hydrogen bond interaction, this suggests a second interaction involving either the acidic $\mathrm{NH}$ or a $\mathrm{N}$-aromatic of diuron, which is absent in cycluron. However, weakly active compounds such as stigmatelline or myxothiazol contain no $\mathrm{NH}$, but still possess a $\mathrm{C}=\mathrm{O}$ without an adjacent nitrogen, pointing it as the minimum structure for PS II inhibition [42]. This is also illustrated by several cyanoacrylates [14]. The presence of one or two adjacent electrondonating, positively charged [15], nitrogens would reinforce the nucleophilic character of this $\mathrm{C}=\mathrm{O}$ group [11], without being directly involved in the interaction.

The role of a second hydrogen bond formed by the acidic NH of terbutryn has been recently demonstrated in the reaction centers of Rhodopseudomonas viridis [18]. This agrees with the hypothesis of a common interaction of different groups of inhibitors [12], with some exceptions $[13,14,42]$, through their $-\mathrm{NH}-\mathrm{CX}-$ moiety. However, a comparison of the $\mathrm{X}$...H distances leads to this being questioned. In uracils, H...H distances are $2.4 \AA$ and $4.95 \AA$ (Fig. 1). In diuron, the stable trans form corresponds to $3.1 \AA$, while the cis form at $2.4 \AA$ is energetically unfavored, although its occurrence cannot be excluded in vivo. In uracils, the carbonyl in position 4 (X...H distance of $4.9 \AA$, similar to the $4.65 \AA$ distance found in triazines) is likely to play a role in vivo, since its suppression results in inactive cyclic ureas [41]. This would imply that more than two hydrogen bonding groups (proton donor or acceptors) within the $\mathrm{Q}_{B}$ pocket play a role in the binding of inhibitors.

Semi-empirical calculations and IR studies of phenol-inhibitors interactions confirm the previous QSAR predictions $[11,12]$ on the influences of substituents on the net charge of the carbonyl, in ureas and amides; that is essentially the charge-enhancing effect of the carbonyl-linked dimethylamino group and, to a lesser extent, the influence (estimated by Hammett $\sigma$ ) of electron-withdrawing or donating substituents on the $\mathrm{N}$-phenyl ring. Equivalent charges and proton-accepting capacities are found in the heterocyclic nitrogens of triazines or pyrimidines, compared to $\mathrm{NH}-\mathrm{CO}$ derivatives. This supports a $\mathrm{C}=\mathrm{O} / \mathrm{C}=\mathrm{N}$ homology, although the characteristics of $=\mathrm{O} \ldots \mathrm{HX}$ and $=\mathrm{N} \ldots \mathrm{HX}$ hydrogen bonds are different [33].

Methylthiopyrimidines can provide further information since they contain only two ring nitrogens, 
one of which is more charged ( -0.44 instead of -0.39 ) and thus a better candidate to form an hydrogen bond. The asymmetrical character of these molecule would allow the determination of which one of the two lateral NH corresponds to the phenyl or benzyl substitutable $\mathrm{NH}$ of triazines [10]. It has been previously shown [21] that the $\mathrm{NH}$-alkyl in position 5 on the pyrimidine ring undergoes harsh steric constraints and that its hydrophobicity does not antagonize triazine resistance, in contrast with hydrophobic N-phenyl of urea/amides [7] or N-benzyl triazines [10]. The $\mathrm{NH}_{2}$ in position 3 cannot be substituted, due to the steric hindrance of the rotating methylthio group in position 2 , where it takes the place of one of the ring nitrogens of triazines. This $\mathrm{NH}_{2}$ would tentatively correspond to the $\mathrm{NH}$ phenyl or benzyl substitutable position or triazines.

Hydrogen bonding has been demonstrated in the bacterial site, but alternate mechanisms might play a role in PS II centers. For example, a dipole-charge interaction could account for part of the in vivo binding energy [38], although it is difficult to explain the great diversity of behavior towards triazine resistance of compounds binding to the same site by a single strong interaction.

\section{Conclusion}

Owing to the conjugated bond character of most PS II inhibitors, the geometrical and electronic properties of these compounds had to be calculated by a quantum method (AM 1), from an initial set of coordinates obtained by a molecular mechanics method (CHARMM or SYBYL). AM 1 brings a significant improvement over MNDO in the prediction of molecular conformations of PS II inhibitors. Other studies [43] showed that this method also provides a good representation of hydrogen bonding. Measured or calculated molecular properties of inhibitors allow to go beyond the limitations of classical QSAR studies and to compare compounds from different series. In the absence of cristal structure of PS II centers, models have to be proposed from the known structures of bacterial reaction centers $[19,20]$. In this respect, improved predictions of conformations and interaction properties of various PS II inhibitors, taking into account different conformers and the flexibility around the calculated minima, would help in building these models.

Comparison of resistant/susceptible chloroplast inhibition is an useful approach since it allows variations of binding strength to be obtained independently of the water/membrane partition. Studies of a large set of molecular structures have already demonstrated the closeness of their binding domains, pointing out some structural features (resistance-antagonizing effects of an hydrophobic N-phenyl or of a nucleophilic carbonyl) which could explain the great diversity of responses of these compounds to an herbicide-resistance mutation.

\section{Acknowledgements}

We thank Prof. J. P. Doucet for helpful advice, Dr. Mathis who made this work possible, A. W. Rutherford for reading the manuscript and Dr. M. Gingold for setting-up software. This work is part of the INRA/CEA convention. 
[1] K. Pfister and C. J. Arntzen, Z. Naturforsch. 34c, 996-1009 (1979).

[2] J. M. Erickson, M. Rahire, P. Bennoun, P. Delepelaire, B. Diner, and J. D. Rochaix, Proc. Natl. Acad. Sci. U.S.A. 81, 3617-3621 (1984).

[3] C. Astier, A. Boussac, and A. L. Etienne, FEBS Lett. 167, 2, 321-325 (1984).

[4] J. Hirschberg and L. McIntosh, Science 222, 1346-1348 (1983).

[5] A. Trebst and W. Draber, Proceed. 4th Int. IUPAC Congress on Pest. Chemistry, Zürich, Pergamon Press, Vol. 3, p. 85 (1978).

[6] W. Tischer and H. Strotmann, Biochim. Biophys. Acta 460, 113-125 (1977).

[7] J. M. Ducruet and R. de Prado, Pest. Biochem. Physiol. 18, 253-261 (1982).

[8] E. P. Fuerst, C. J. Arntzen, K. Pfister, and D. Penner, Weed Science 34, 344-353 (1986).

[9] W. Oettmeier, K. Masson, C. Fedtke, J. Konze, and R. R. Schmidt, Pest. Biochem. Physiol. 18, 357-367 (1982).

[10] G. Gardner, J. R. Sanborn, and J. R. Goss, Weed Science 35, 763-769 (1987).

[11] D. E. Moreland, Progress in Photosynthesis Research, Vol. III, 1693-1711 (1969).

[12] C. Hansch, Progress in Photosynthesis Research, Vol. III, 1685-1692 (1969).

[13] A. Trebst and E. Harth, Z. Naturforsch. 29c, 232-235 (1974).

[14] J. L. Phillips and J. N. Huppatz, Z. Naturforsch. 39c, 617-622 (1984).

[15] A. Trebst, W. Donner, and W. Draber, Z. Naturforsch. 39c, 405-411 (1984).

[16] N. E. Good, Plant Physiol. 36, 788-803 (1961).

[17] C. J. Van Assche and P. M. Carles, ACS Series 181, $1-22$ (1982).

[18] H. Michel, O. Epp, and J. Deisenhofer, EMBO J. 5, 2445-2451 (1986).

[19] A. Trebst, Z. Naturforsch. 42c, 742-750 (1987).

[20] H. Michel and J. Deisenhofer, Biochemistry 27, 1, 1-7 (1988).

[21] J. M. Ducruet and R. Scalla, Z. Naturforsch. 40c, 388-390 (1985).

[22] R. R. Brooks, R. E. Brucoleri, B. D. Olafson, D. J. States, S. Swaminathan, and M. J. Karplus, J. Comp. Chem. 4, 187-217 (1983).
[23] J. G. Vinter, A. Davis, and M. R. Saunders, J. Computer-Aided Mol. Design 1, 31-51 (1987).

[24] M. J. S. Dewar and W. Thiel, J. Amer. Chem. Soc. 99, 4899-4917 (1977).

[25] M. J. S. Dewar, E. G. Zoebisch, E. F. Healy, and J. J. P. Steward, J. Amer. Chem. Soc. 107, 3902-3909 (1985).

[26] J. M. Ducruet, Advances in Photosynthesis Research IV, 1, 21-24 (1983).

[27] J. M. Ducruet, Thesis, Univ. Paris-Sud Orsay (1986).

[28] R. G. Baugham, D. D. Sams, B. J. Helland, and R. A. Jacobson, Cryst. Struct. Comm. 9, 885-889 (1980).

[29] M. J. S. Dewar and E. G. Zoebisch, J. Mol. Structure (Theochem) 180, 1-21 (1988).

[30] E. M. Arnett, L. Joris, E. Mitchell, T. Murty, T. M. Gorrie, and P. Schleyer, J. Amer. Chem. Soc. 92, 8, 2365-2377 (1970).

[31] M. D. Joesten and L. J. Schaad, in: Hydrogen Bonding, p. 221, Marcel Dekker, New York 1974.

[32] P. P. Rastogi and G. Zundel, Biochem. Biophys. Res. Commun. 99, 804 (1981).

[33] G. Zundel, J. Mol. Structure 177, 43-69 (1988).

[34] T. M. Ward and J. B. Weber, Spectrochim. Acta $25 \mathbf{A}$, 1167-1176 (1969).

[35] K. Morokuma, Accounts Chem. Res. 10, 294-300 (1977).

[36] F. A. Momany, R. F. McGuire, J. F. Yan, and H. A. Scheraga, J. Phys. Chem. 74, 12, 2424-2438 (1970).

[37] A. Johansson, P. Kollmann, S. Rothenberg, and J. McKevley, J. Amer. Chem. Soc. 96, 12, 3794-3800 (1974).

[38] L. L. Shipman, J. Theor. Biol. 90, 123-148 (1981).

[39] R. Foster, Organic charge-transfer complexes, pp. 1-93, Academic Press, 1969.

[40] W. Tischer and H. Strotmann, Z. Naturforsch. 34c, 992-995 (1979).

[41] S. G. Boots, M. R. Boots, and D. E. Moreland, J. Med. Chem. 15, 330-332 (1972).

[42] K. M. Giangiacomo, D. E. Robertson, M. R. Gunner, and P. L. Dutton, Progress in Photosynth. Res., Vol. II, 6, 409-412 (1987).

[43] G. Buemi, F. Zuccarelo, and A. Raudino, J. Mol. Structure (Theochem) 164, 379-389 (1988). 